\title{
Policy Support Through Modeling and Evaluation: Methodological Challenges and Practical Solutions
}

\author{
Ousmane Badiane, Christian Henning, and Eva Krampe
}

In 2003, African leaders endorsed the Comprehensive Africa Agriculture Development Programme (CAADP) as the action plan for putting agriculture back on Africa's development agenda. A critical challenge for all policymakers wrestling with economic development and poverty reduction in Africa-as well as everywhere else in the world-is how to assess which programs and policies actually work. A corollary to this challenge is to identify, among the programs that do work, those that provide the best value for money (OECD 2004). A key approach of CAADP is the promotion of evidence-based policies, where it has been fully recognized that policy impact evaluation is an important prerequisite for evidence-based policy processes. In the literature, quantitative policy impact evaluation is considered a key method for generating scientific knowledge on which policies actually work best in a country. However, the incorporation of this knowledge into the political decisionmaking process is a non-trivial process. Hence, beyond generating knowledge, incorporating it into the political process is another prerequisite of an effective evidence-based policy process. In this regard, it is widely expected that active stakeholder participation will not only increase politicians' incentives to select the most efficient policies, but also increase the capacity of policy learning inherent in a political system (see e.g. Ball 1995). The principles of review, accountability, and inclusivity, which are core principles of CAADP, reflect the belief that participatory policy processes at the continental, regional, and

O. Badiane (ه)

International Food Policy Research Institute, Washington, DC, USA

e-mail: obadiane@cgiar.org

C. Henning

Department of Agricultural Economics, University of Kiel, Kiel, Germany

E. Krampe

European Investment Bank, Luxembourg, Luxembourg

C. Henning et al. (eds.), Development Policies and Policy Processes in Africa,

Advances in African Economic, Social and Political Development,

DOI 10.1007/978-3-319-60714-6_1 
national levels lead to improved coordination, mutual learning, and the adoption of best practices, which together should result in improved policy planning and execution, better growth, and poverty reduction outcomes.

Linking economic analysis to policy formulation and outcome is a very complex and tedious process. The problem is not just one of applying rigorous economic theory to high-quality data in order to tackle relevant questions. This is difficult enough but may still be the easiest part. A greater challenge is for the knowledge and insights generated from policy research and analysis to find their way into the decisionmaking process. And even when it does, science-based evidence forms only one part, and often not the most important part, of the understanding that influences the decisionmaking process, where imperfect political competition often induces biased incentives for politicians, impeding the implementation of available best-practice politics.

Contained in the present volume are a selection of tools and methodologies that can help to tackle the complexities in the analysis of policy processes and outcomes under the implementation of the CAADP agenda. The contributions go beyond the innovative methods and tools applied for quantitative policy impact analyses by international organizations like the Organisation for Economic Co-operation and Development (OECD), the World Bank or the European Union, as they also to examine the process behind the choice of policies and the factors that determine the likelihood of their adoption and implementation. It is the product of a workshop organized by the University of Kiel (CAU), the International Food Policy Research Institute (IFPRI) and the Poverty Reduction, Equity, and Growth Network (PEGNet) of the Kiel Institute of World Economy in 2011. The workshop brought together scholars working in the field of policy modeling and evaluation at the microeconomic and macroeconomic level or in the field of quantitative modeling of policy processes.

The various contributions in these proceedings are not targeted only to experts and interdisciplinary scholars working on empirical or theoretical research using quantitative policy modeling and evaluation techniques. They are also intended for technical experts, including policymakers and analysts from stakeholder organizations, who are involved in formulating and implementing policies to reduce poverty and to increase economic and social well-being in African countries.

In order to facilitate discussion on the recently developed evaluation methodologies and their applicability in the context of CAADP and its evaluation mechanisms, we first develop a general assessment framework. This framework incorporates guidelines and principles not only for economic policy impact evaluation, but also for methodological approaches and tools assessing policy processes quantitatively.

\section{A General Framework for Policy and Policy Process Evaluation}

\subsection{The Basic Setup}

At an abstract level, impact evaluation of a given policy instrument, say ' $\gamma$ ', includes two different aspects. First, it is necessary to assess the technical 
transformation of policy $\gamma$ into relevant policy outcomes $\mathrm{z}$. This transformation is captured by the technical transformation function $T(z, \gamma)$, which links specific outcomes to the policy in question. Second, different policy outcomes have to be evaluated from the viewpoint of society. Formally, welfare analysis is a tool that provides for an adequate evaluation criterion, i.e., an index function $E C(z) . E C(z)$ transforms each state of the world $\mathrm{z}$ into an index number, and by doing so allows for a consistent ordering of states. For example, $E C(z 1)>E C(z 2)$ implies that state $z 1$ is preferred to state $z 2$. Accordingly, if we were to know both functions, $E C$ and $T$, evaluation would be a purely technical task. For a set of available policies $\gamma \in A$, where $\mathrm{A}$ is the set of all feasible policies a society can choose from, the policy with the maximal evaluation value $E C$ would be implemented:

$$
E(\gamma)=\operatorname{Max}\{E C(z) \mid T(z, \gamma)=0\}
$$

In reality, however, an empirical specification of both the welfare function $E C$ and the technical transformation function $\mathrm{T}$ is extremely complex and difficult. Conventional policy impact analyses that focus on identifying the technical transformation function usually assume a welfare function as exogenously given. The main argument for this assumption is that a comprehensive modeling of the decisionmakers' evaluation of his or her preferred outcome and of the political decisionmaking processes cannot be attained with the research approaches at hand. A corollary to this argument is that research can at best focus on the technical relationship ( $\mathrm{T}$ ) between alternative policies and outcomes, thereby offering evidence-based guidance for decisionmaking.

Even when assuming an exogenously given welfare function $(E C(\gamma))$, policy impact evaluation still remains a quite complex undertaking, because it is by no means straightforward to specify the technical transformation function. This results from many different reasons. First, policy outcomes are often formulated in terms of abstract, higher level policy objectives, e.g., equal quality of life conditions in rural and urban regions. These objectives need to be transformed into a set of measurable policy outcome indicators, which then can be systematically related to policy programs. Second, the relationship between policy programs and lower level policy objectives, as well as the relationship between the latter and higher level objectives, all reflect the behavior of people and thus require a theory of human behavior. Therefore, a quantitative specification and assessment of the technical relationship between inputs of a policy program and their effects on higher level policy objectives remains a tricky business. More importantly, disentangling the effects of a specific policy program becomes more challenging when many policy programs are implemented simultaneously. 


\subsection{Policy Impact Evaluation}

The framework includes three major components, which are discussed in the subsequent sections. They include policy evaluation criteria, intervention logic, and evaluation methods.

\subsubsection{Policy Evaluation Criteria}

Clear and relevant evaluation criteria should be the starting point of developing adequate evaluation tools. Five such evaluation criteria can be distinguished (European Commission 2004):

- Relevance: What are the general needs, problems, and issues, both short and long term, that are being targeted under the policy programs? Given the identified needs, a hierarchy of general, intermediate, and specific program objectives can be derived, where objectives at a lower-level function as inputs to achieve objectives at the next higher level.

- Effectiveness: To what extent does a policy program deliver results or outputs that correspond to program objectives? Effectiveness is a technical relationship between program objectives and program results.

- Efficiency: To what extent are program objectives achieved at the lowest costs? Efficiency is a technical relationship between program inputs and program results.

- Utility: To what extent does a policy program contribute to the identified needs?

- Sustainability: To what extent does the utility of a program last after the program has been terminated?

\subsubsection{Intervention Logic}

Any evaluation of policy programs is based on intervention logic, or the systematic derivation of the hierarchy of measurable objectives relating a policy program, all the way from specific, operational objectives to more abstract, general policy objectives. The intervention logic, as a central evaluation tool, thus corresponds to a set of hypothetical cause-and-effect linkages that describe how an intervention is expected to attain its global objectives.

To this end, an intervention can be systematically subdivided into specific elements that are related to each other at specific stages of the project, as demonstrated in Fig. 1.

In general, we can distinguish program implementation and program effects. Any policy program starts with its implementation; for example, financial inputs or administrative capacities are used to realize specific outputs. In an investment program, for example, the inputs might correspond to a specific amount of financial resources that are spent to subsidize investment projects on farms. The output of 


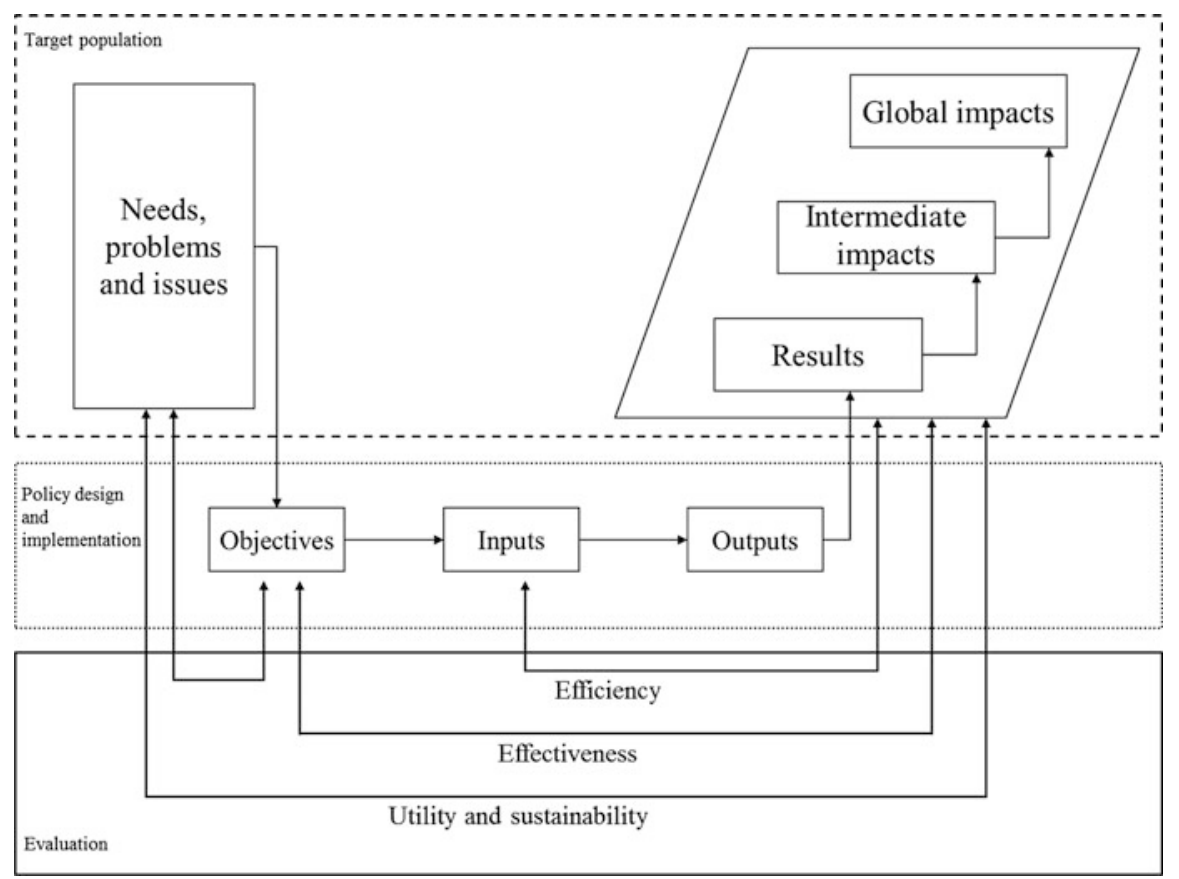

Fig. 1 Schematic presentation of a policy impact evaluation framework. Source: Authors, based on European Commission (2004)

this investment project corresponds to the number and type of investment programs that are actually subsidized. Depending on the applied implementation procedure, the number and type of investment projects might differ. In particular, if farms are heterogeneous, the type of farms that will be subsidized under a program might differ according to applied implementation procedures.

The outputs of a project generate effects, which can be further subdivided into results (short-term effects that occur at the level of direct target groups) and impacts (medium- and long-term effects). Medium-term impacts involve effects on both direct and indirect beneficiaries/recipients of assistance, while long-term effects correspond to the global impacts of a policy program. Moreover, the global impact of a policy program is related to the general needs, problems, and issues identified at a higher policy level, where the program's utility is defined as its contribution to identified needs (see Fig. 1).

\subsubsection{Evaluation Methods}

Any intervention logic for policy programs is based on theory. Two different evaluation approaches can be distinguished: (1) qualitative and (2) quantitative models. Qualitative models, for example the logical framework matrix, simply 
provide a qualitative description of the intervention logic. Quantitative impact evaluation is based on a quantitative specification of relevant cause-and-effect linkages. Quantitative evaluation models can be further subdivided into model based, and econometric policy evaluation approaches.

\section{Model-Based Policy Evaluation}

The common approach in economics for specifying an intervention logic of policy programs is to apply a theoretical model. Different approaches are available for model-based policy evaluation, ranging from simple incidence analysis, to more advanced micro and macro behavioral models, to complex micro-macro linkages models. These approaches differ regarding the set of agents and actions they consider, as well as the assumed coordination mechanism of individual actions. The complexity increases with the number of agents and the level of behavioral response that models explicitly take into account.

\section{Simple Incidence Analysis}

Simple incidence analysis ignores any behavioral response of involved actors. For example, an ex ante evaluation of a planned tax reform or a planned investment subsidization project may be based on a simple arithmetic representation of the incidence of a tax or subsidy, without simulating any policy response of involved agents (Bourguignon et al. 2002). However, policies often have important price or income effects, which in turn induce changes of agents' behavior, such as changes in supply, consumption, or labor demand behavior. A behavioral model is needed in this case.

\section{Micro-simulation Partial Equilibrium Models}

In contrast to incidence models, behavioral models take the policy responses of involved actors explicitly into account. However, there exist different types of behavioral models that differ regarding the level of response they take into account. Micro-simulation models take only the direct policy response of involved actors into account. Basically, these models are partial equilibrium models that neglect the indirect effects of policy programs resulting from agents' interaction at the macro level. The structure of these models can be described as follows:

$$
\begin{gathered}
x_{i}=F\left(\xi, \varphi_{i}, \gamma\right) \\
z=G\left(x_{i}, \xi, \varphi_{i}, \gamma\right)
\end{gathered}
$$

where $x_{i}$ denotes the vector of relevant behavioral variables of an individual agent $i$, $\varphi$ and $\xi$ denote the general and agent-specific exogenous variables, respectively, 
that determine individual behavior, $\gamma$ is the evaluated policy, and $\mathrm{z}$ is the policy outcome.

For a policy evaluation, the behavioral Eq. (2) has to be estimated based on survey data. Given the specified Eqs. (2 and 3), the impact of different policies can be simulated. The relevant agents are, for example, all households or firms in a specific region. Often census data is used to provide information on their individual characteristics. The response of all relevant agents can be estimated using Eq. (3), given this information. The behavioral function $F()$ is either specified as a reduced form or an explicit functional form is derived from the underlying microeconomic optimization problem. ${ }^{1}$ All micro-simulation models neglect the interaction of individual agents. Micro-simulation models are not adequate tools for policy evaluation if behavioral response at the micro level crucially depends on interactions among actors at the macro level.

\section{Macro or General Equilibrium Models}

General equilibrium models are designed to include policy effects at the macro level (Bourguignon et al. 2002). The most simple general equilibrium models are linear models, e.g., regional input-output models or social accounting matrices (SAMs). More advanced (nonlinear) general equilibrium models are standard computable general equilibrium (CGE) approaches. With the CGE approach, policy-induced behavioral responses at the micro level are explicitly transmitted onto the overall economy via induced price changes at the macro level. However, the explicit inclusion of macro-level effects comes at a cost. Standard CGE models are highly aggregated, assuming only a small number of representative economic agents (firms and households). Theoretically, CGE models could be more disaggregated into a large number of heterogeneous firms and households, but they become difficult to solve with the computer capacities usually available. Moreover, the empirical estimation of functional parameters of the CGE model is also a major problem due to very limited adequate data. Thus, although CGE models can be linked with a micro-accounting model, if relevant policy evaluation criteria include distributional effects, aggregated CGE models are less appropriate tools for an adequate policy evaluation (see Chapter "Sequential Macro-Micro Modelling with Behavioral Microsimulations" in this volume).

\footnotetext{
${ }^{1}$ A very interesting nonparametric approach applies propensity score matching techniques, originally developed as an advanced ex post evaluation technique, to simulate policy effects at the micro level (Todd and Wolpin 2006). An advantage of a nonparametric estimation strategy, when compared to parametric approaches, follows from the fact that the former are less demanding regarding data requirements and do not require any specific functional form assumptions (Todd and Wolpin 2006). However, in many cases nonparametric approaches are not applicable to ex ante policy evaluation, but stronger modeling assumptions, e.g., functional form assumption, have to be made.
} 


\section{Micro-Macro Linked Models}

In order to deal with computational capabilities and empirical complexity issues, some authors suggest micro-macro linked models, which combine microsimulation models and macro general equilibrium models (Robilliard et al. 2001). A full integration of micro and macro models is hard to achieve, although technically possible (Bourguignon et al. 2008). Therefore, often a sequential approach is applied where first macro models are solved and central variables of the macro model are then incorporated into corresponding micro models (Robilliard et al. 2001). Standard CGE models assume that interactions among individual agents are coordinated through perfect markets. In reality, transaction costs as well as market power imply imperfect competition and thereby perfect markets rarely exist. Of course, the standard CGE approach can be extended to include market imperfection due to transaction costs or market power. But these extended approaches are technically more demanding and therefore have been rarely applied for policy evaluation. More feasible alternatives include a linked or sequential micro-macro model, in which different micro-behavioral models can be combined with macro equilibrium models. Linked micro models include farm-household models incorporating non-market activities or nonlinear transaction costs (Singh et al. 1986).

\subsection{Econometric Policy Evaluation}

A general problem of model-based policy evaluation is that models are often quite complex, and an empirical specification of the model is often impossible due to limited data. Central causal relationships assumed by a model cannot easily be verified or tested empirically. Hence, it is necessary to develop methods that are able to provide empirical evidence suitable for guiding policy. This is not an easy task, because it refers to causal inferences that require special research methods that are not always easy to communicate due to their technical complexity.

This section surveys econometric methods that the economics profession has used increasingly over the past decade to estimate causal effects of policies. A causal linkage can be specified as a simple binary relationship between program participation and a relevant performance variable, e.g., the impact of participation in a training program on farm profit or employment. The most straightforward way to measure the policy impact in this context would be to compare the performance of a program participant with the counterfactual performance of the participant without participation. A major challenge of this approach is to simultaneously observe both performances, assuming participation and the counterfactual performance. The different methods applied in this area are designed to distinguish accidental association from causation. They provide empirical strategies to identify the causal impact of different reforms on any kind of policy outcomes.

The best approach to identifying program impact on a given performance variable is to conduct field experiments, i.e., to undertake a random selection of 
the units of interest into participating (treatment) and non-participating (control) groups in a policy program. Based on a comparison of the average performance of the randomly selected treatment and control groups, the impact of the policy program can be statistically evaluated. While experimental approaches can be applied for ex post and ex ante policy evaluation, a huge drawback of this approach is that it is extremely expensive and, for many policies, it is impossible to design sophisticated field experiments allowing a quantitative evaluation. In this case, other econometric procedures based on observational data are available that allow one to identify the true impact of a policy program assuming a non-random selection of treatment and non-treatment groups. These econometric approaches can be subdivided into non-parametric and parametric approaches. An increasingly popular non-parametric approach to policy evaluation is matching on observable factors, especially propensity score matching (PSM) (Caliendo and Hujer 2006). Matching and other econometric methods that build on the idea of controlling for observable factors have clear limitations. The policy impact is very often determined by factors that are unobserved by the researcher. This implies that PSM delivers biased results or that policy impact is heterogeneous across participants. In order to get around these problems, alternative methods have been developed. They are used to emulate experimental settings using observational data, i.e., 'natural' experiments, such as the instrumental-variable approach and the regressiondiscontinuity approach, or panel-data-based methods that aim to account for endogeneity.

A general cutback of all statistical models, however, is the fact that they are limited to causal inferences, i.e., empirical testing on the question of whether a given policy program achieved its intended outcome or not. In general, they are not alone suitable to elucidate the question of why or how a policy program works. Therefore, the best approach to policy evaluation is to combine model-based and econometric methods as complementary approaches, where econometric techniques are applied to identify causal relations between specific policy programs $(\gamma)$ and central economic factors $(\theta)$, and model-based techniques to analyze the impact of a change in these economic factors on central outcome indicators $(z)$. The transformation function $T(z, \gamma)$ is separated into two parts: $(i)$ a policy impact function $\theta=P I(\gamma)$ describing the relationship between policy interventions and the economic factors $\theta$, and (ii) a policy outcome function $P O(z, \theta)$ describing the linkages between the economic factor $\theta$ and policy outcomes z. Econometric methods are more suitable for tackling the policy impact function, whereas economic models do a better job of tracking the policy outcome function.

\subsection{Modeling and Evaluation of Policy Processes}

Many countries around the globe continue to apply suboptimal policies despite available scientific knowledge demonstrating the existence of policy instruments that would lead to more desirable overall economic and social outcomes. For 
example, there is evidence that many developing countries that still largely depend on agriculture, especially in Africa, underinvest in this sector. They especially spend too little budget on, e.g., agricultural research and extension which are areas of public investment with high returns in terms of growth and poverty reduction (Fan and Rao 2003).

Thus, evidence-based policy formulation includes, beyond the generation of scientific knowledge, the effective incorporation of this knowledge into the political decisionmaking process. The latter is by nature complex and dynamic, involves multiple actors (individuals and organizations), and is defined by local political, social (cultural and belief systems) and institutional realities (bureaucratic structures and capacities). Essentially, the policy process corresponds to an aggregation of the heterogeneous preferences of different stakeholder groups into a common policy decision. In representative democracies, preference aggregation is subdivided into two steps. First, heterogeneous voter preferences are transformed into the corresponding preferences of a subset of political representatives via democratic elections. A central property of democratic elections is their representativeness, i.e., the correspondence between the distribution of preferences among elected representatives with the distribution of preferences among the voting population. Second, the heterogeneous preferences of political representatives are aggregated into a final political decision via legislative voting procedures.

The above process can be modeled as follows: Let a society comprise of $n_{I}$ different groups, where $I=1, \ldots, n_{I}$ denotes the index of stakeholder groups. Further, let $U_{I}(z)$ denote the utility function of an individual group member $i \in I$, and $w_{I}$ denotes the population share of group I. Then, an ideal policy process can be defined as a process that results in a policy choice $\gamma^{*}$ :

$$
\gamma^{\text {ideal }}=\arg \max _{\gamma} \sum_{I} w_{I} U_{I}(z) \quad \text { s.t. } \quad T(z, \gamma)=0
$$

where $T(z, \gamma)$ is the political technology, that is, the subset of all policy outcomes z that can be optimally achieved by available policies $\gamma$, given existing political knowledge.

Differences between observed and ideal policy choices result from two different sources. First, a biased aggregation of society preferences, i.e., real policy processes, results in different political weights of groups when compared to the ideal democratic process. At a theoretical level, existing political economy models highlight this bias as a main cause of persisting inefficient policies. Biased political weights correspond to biased incentives of elected politicians, and result from asymmetric lobbying activities (Grossman 1994) or biased voter behavior (Bardhan and Mookherjee 2002). More recently, Persson and Tabellini (2000) highlight the role of formal constitutional rules as determinants of politicians' incentives to misrepresent society interests and choose inefficient policies.

Beyond biases resulting from the aggregation of society preferences, a second source of biased policy is that the true political technology is not fully known by the relevant political actors. Understanding the complex relationship between policy 
instruments and induced policy outcomes is difficult. As a result, political actors use simple mental models to understand how policies translate into outcomes. We call these simple mental models policy beliefs. Based on their policy beliefs, political actors derive their individual preferences with respect to policies. Similarly, some authors have recently highlighted the role of biased voter beliefs as a main determinant of inefficient policy choices (Beilhartz and Gersbach 2004; Bischoff and Siemers 2011; Caplan 2007). In particular, the work by Caplan (2007) has been highly recognized in public choice literature, as he has collected an impressive amount of evidence showing persistently biased voter beliefs. Based on his empirical findings, Caplan (2007) draws the rather pessimistic conclusion that democratic mechanisms of preference aggregation naturally lead to the choice of inefficient policies.

In this context, two key underlying premises that define the framework of evaluating policy processes are adopted here. The first premise is that biased voter beliefs imply biased voter behavior and hence a biased aggregation of preferences. The second premise is that politicians and lobbyists do not fully understand the complex relationship between political instruments and desired policy outcomes. Hence, beyond biased incentives, lack of political knowledge becomes another important cause of policy failure.

The evaluation of policy processes can be based on the comparison between actual, implemented policy choice $\gamma^{\text {actual }}$ and the ideal policy choice $\gamma^{\text {ideal }}: \| \gamma^{\text {actual }}$ $-\gamma^{\text {ideal }}\|$.$\| \| is the Euclidian distance. That is, the evaluation of policy processes$ should be able to identify political performance gaps as defined above. Policy diagnosis should also allow for the separation of identified performance gaps into incentive-induced and knowledge-based gaps. Finally, a comprehensive evaluation of policy processes should provide the possibility of developing a political therapy, i.e., the derivation of a strategy to reduce identified performance gaps. The latter in particular calls for model-based evaluation methodologies.

Our methodology is derived from the model described in Fig. 2.

Schematically, a dynamic policy process includes a sequence of political decisionmaking based on actors' policy beliefs, the transformation of the selected policy into outcomes via induced policy responses in the economic system, the translation of economic and political outcomes into political support via elections and lobbying and policy learning, i.e., the updating of policy beliefs (see Fig. 2). Policy learning occurs via two mechanisms. First, based on observed outcomes, political actors engage in observational policy learning, i.e., they update their policy beliefs by comparing observed outcomes with the policy outcomes they expected based on their initial policy beliefs. Individual observations, however, are noisy and hence individual observational learning is limited. Accordingly, political actors engage in communication learning, i.e., they update their policy beliefs based on political beliefs communicated by other actors. Within policy processes, communication learning occurs via political mass communications, i.e., the formation of a public opinion, as well as via exclusive political communication within a political elite comprising of relevant politicians and stakeholder organizations. Interestingly, the social organization of political communication processes has a significant 
Fig. 2 Schematic representation of a policy process. Source: Authors

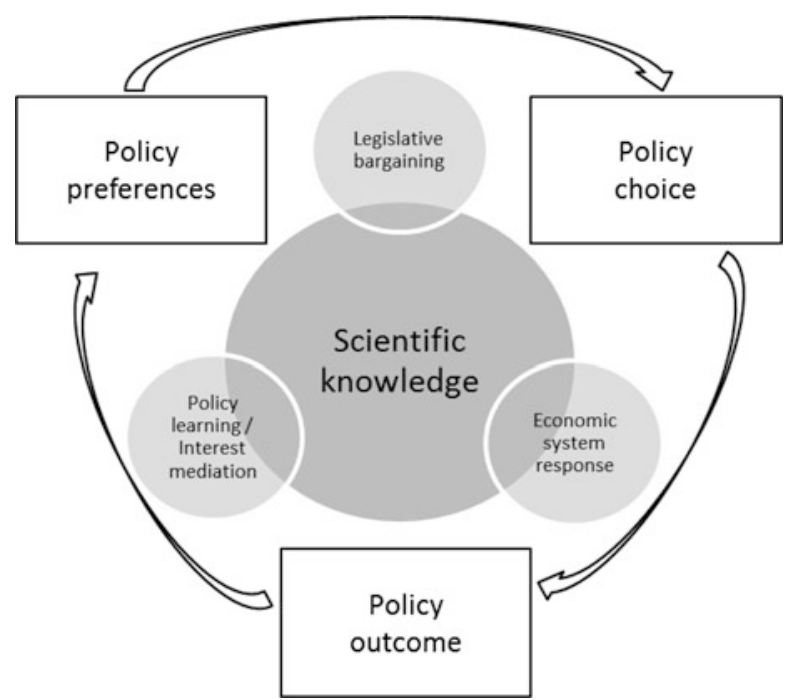

impact on the speed of policy learning. In particular, the structure of a communication network has a significant impact on its capacity to aggregate decentralized information within a political elite. Moreover, network structure also determines the influence of individual organizations on the policy beliefs of relevant politicians and hence the direction of the bias of political decisionmaking.

Few studies have explicitly mapped out the above processes in explaining the poor past performance of policy reforms and investment strategies, particularly in the agricultural sector. Most have offered narratives based on historical accounts, pointing to the strong role of powerful personalities, vested interests, corruption, and external pressures, in influencing policy outcomes (Clay and Schaffer 1984; Juma and Clark 1995; Keeley and Scoones 2003; Young 2005).

The challenge of analyzing participatory and evidence-based policy processes empirically is to develop an applicable model framework that allows for quantitative modeling of political decisionmaking and policy-learning processes, including the endogenous formation of a legislator's political preferences and policy beliefs. In this context, four components of a political process framework can be distinguished (see Fig. 2): (i) the derivation of politicians' incentives from electoral competition and lobbying, i.e., modeling voter behavior and interest group activities; (ii) modeling legislative bargaining, i.e., the derivation of a collective policy decision by a set of heterogeneous legislators based on constitutional rules; (iii) economic modeling of policy impacts, i.e., the transformation of policies into outcomes; and (iv) modeling of policy learning, i.e., the formation and updating of policy beliefs via observational and communication learning. The existing evaluation literature focuses only on the third component, although the other three components represent aspects of the policy process that play a key role in explaining why some nations succeed while others fail in adopting efficient and effective policies. 
The current volume assembles different contributions, which together provide a comprehensive set of innovative quantitative approaches that can be used to model these various aspects of the policy process. In particular, Chapter "Modeling and Evaluation of Political Processes: A New Quantitative Approach" presents an evolutionary computable general political economy equilibrium (eCGPE) model, combining all four components listed above as an integrated quantitative approach to model and evaluate real policy processes.

\section{Contributions to This Volume}

Following this overview of methodological approaches to quantitative policy evaluations, the twelve contributions to these proceedings can be subdivided into two parts: I. Theory and application of quantitative policy impact evaluation models, and II. Theory and application of quantitative approaches to model and evaluate policy processes.

Part I is subdivided into three sections: 1. Macroeconomic Models, 2. MicroEconometric Models and 3. Micro-Macro Linked Models. As an opener to Sect. 1, O. Badiane, S. Odjo and F. Wouterse present their results for CAADP-reform strategies and the long-term outlook for growth and poverty reduction of Economic Community of West African States (ECOWAS) member countries (Chapter "Comparative Analysis of Strategies and Long Term Outlook for Growth and Poverty Reduction among ECOWAS Member Countries"). They use a recursive dynamic CGE model linked with a micro accounting model, transforming economic macro shocks into individual household income changes for their analysis. The second contribution of the section is by M. Wiebelt, K. Pauw, J.M. Matovu, E. Twinmukye and T. Benson. They provide a comprehensive analysis of the different policy options to use oil revenues in Uganda (Chapter "How to Spend Uganda's Expected Oil Revenues? A CGE Analysis of the Agricultural and Poverty Impacts of Spending Options"). As their analysis focuses on the implication on poverty, a recursive dynamic CGE model is linked with a micro accounting model transferring average income changes of representative households generated in the CGE model into a corresponding change of individual household income at the micro level.

Econometric evaluation techniques are applied and discussed by S. Benin et al. in Chapter "Impact of the National Agricultural Advisory Services (NAADS) Program of Uganda: Considering Different Levels of Likely Contamination with the Treatment". In particular, they develop and apply innovative matching approaches to assess the impact of an agricultural advisory services program in Uganda based on observational data.

Furthermore, Sect. 2 contains two innovative micro-macro-linked approaches. In Chapter "Modeling Agricultural Growth and Nutrition Linkages: Lessons from Tanzania and Malawi", K. Pauw applies a CGE model that is sequentially linked with a microeconomic nutrition demand model to analyze the impact of different 
growth strategies on income growth and nutrition in Tanzania and Malawi. J. Lay derives and applies a macroeconomic CGE model that is sequentially linked with a reduced form model of households' occupational choices on formal and informal labor markets (Chapter "Sequential Macro-Micro Modelling with Behavioral Microsimulations"). The micro model explicitly includes household's fixed effects to include unobserved heterogeneity among households into the structural labor market model. The approach is used to empirically analyze poverty and the distributional implications of Doha round scenarios in Brazil and poverty and the distributional implications of the Bolivian gas shock.

Part II focuses on innovative quantitative models to evaluate evidence-based and participatory policy processes under CAADP. In particular, an eCGPE approach is theoretically derived and empirically applied to the CAADP reform process in Malawi. It is demonstrated how political performance and incentive gaps can be identified and quantitatively calculated using an eCGPE. This part opens with the presentation of the complete eCGPE framework by C. Henning (Chapter "Modeling and Evaluation of Political Processes: A New Quantitative Approach"). In particular, the theories used to develop an eCGPE, which includes an economic, a legislative decisionmaking, an interest mediation, and a political belief formation module, are explained. The other contributions of the section present findings from the empirical application of the framework to Malawi's policy process.

Chapters "A Network Based Approach to Evaluate Participatory Policy Processes: An Application to CAADP in Malawi" and "The Formation of Elite Communication Networks in Malawi: A Bayesian Econometric Approach" focus on the findings from the political belief formation module. Applying social network theory and methods, they analyze collective political belief formation of governmental and non-governmental actors through communication learning in networks. C. Henning and E. Krampe (Chapter "A Network Based Approach to Evaluate Participatory Policy Processes: An Application to CAADP in Malawi") also develop an evaluation framework for participatory policy processes based on the political belief formation module. C. Aßmann, E. Krampe and C. Henning (Chapter "The Formation of Elite Communication Networks in Malawi: A Bayesian Econometric Approach") test some theoretical hypotheses on the determinants of communication ties among key national stakeholder organizations, donors and central political actors. They apply an adaptation of the Bayesian estimation scheme for binary probit models, which can deal with missing values inevitably occurring within survey data.

L. Seide, C. Henning, and S. Petri (Chapter "Voter Behavior and Government Performance in Malawi: An Application of a Probabilistic Voting Model") present an analysis of voter behavior and its impact on governmental accountability and capture. They derive the implications of voter behavior on governmental accountability and capture using probabilistic voting theory.

The final chapter of Part II is by C. Henning, J. Hedtrich, L. Sene, and E. Krampe. They use the eCGPE model to provide a comprehensive analysis of the economic impacts of policy options and knowledge and political incentive gaps 
in Malawi (Chapter "Whither participation? Evaluating Participatory Policy Processes Using the CGPE Approach: The Case of CAADP in Malawi").

The book closes with two chapters summarizing the central practical policy implications of the presented scientific work. In particular, M. Johnson discusses how quantitative policy monitoring and evaluation systems can be translated into political action based on the empirical example of the strategic analysis and knowledge support system (SAKSS) implemented within CAADP (Chapter "Strategic Analysis and Knowledge Support Systems (SAKSS): Translating Evidence into Action"). In Chapter "Lessons Learned and Future Challenges", C. Henning and O. Badiane present lessons learned for practical policy implementations by highlighting the book's main findings in the areas of economic modeling of growth-poverty and policy-growth linkages, as well as political economy modeling of participatory policy processes. Beyond presenting innovative methodological approaches, the empirical studies in this book also shed light on the role of voters, stakeholders, and donors in participatory policy processes, and provide convincing evidence that beyond constitutional rules, policy beliefs and policy network structures are important determinants of government performance. The chapter also highlights the future outlook and challenges to the modeling and evaluation of policies and political processes.

\section{References}

Ball, R. 1995. Interest groups, influence and welfare. Economics and Politics 7 (2): 119-146.

Bardhan, P., and D. Mookherjee. 2002. Relative capture of local and central governments: An essay in the political economy of decentralization. Working Paper C99-109. Hong Kong: Center of International and Development Economics Research.

Beilhartz, H.-J., and H. Gersbach. 2004. General equilibirium effects and voting into a crisis. Center for Economic and Policy Research (CEPR) Discussion Paper 4454.

Bischoff, I., and L.-H. Siemers. 2011. Biased beliefs and retrospective voting: Why democracies choose mediocre policies. Public Choice 156 (1-2): 163-180.

Bourguignon, F., L. P. da Silva, and N. Stern. 2002. Evaluating the poverty impact of economic policies: Some analytical challenges. Mimeo. Washington, DC: The World Bank.

Bourguignon, F., C. Diaz-Bonilla, and H. Lofgren. 2008. Aid, service delivery, and the millennium development goals in an economy-wide framework. Policy Research Working Paper 4683. Washington, DC: The World Bank.

Caliendo, M., and R. Hujer. 2006. The microeconometric estimation of treatment effects - An overview. Journal of the German Statistical Society/Allgemeines Statistisches Archiv 90 (1): 197-212.

Caplan, B. 2007. The myth of the rational voter - Why democracies choose bad politics. Princeton: Princeton University Press.

Clay, E., and B. Schaffer. 1984. Room for Manoeuvre; An exploration of public policy in agricultural and rural development. London: Heineman Educational Books.

European Commission. 2004. Evaluating EU activities? A practical guide for the commission services. Luxembourg: Office for Official Publications of the European Communities. 
Fan, S., and N. Rao. 2003. Public spending in developing countries: Trends, determination and impact. EPTD Discussion Paper 99. Washington, DC: International Food Policy Research Institute.

Grossman, J.B. 1994. Evaluating social policies: Principles and U.S. experience. The World Bank Research Observer 9 (2): 159-180.

Juma, C., and N. Clark. 1995. Policy research in sub-Saharan Africa: An exploration. Public Administration and Development 15 (2): 121-137.

Keeley, J., and I. Scoones. 2003. Understanding environmental policy processes: Cases from Africa. London: Earthscan.

OECD (Organisation for Economic Co-operation and Development). 2004. Analysis of the 2003 CAP Reform. Number 16. 2003. Paris: OECD.

Persson, T., and G. Tabellini. 2000. Political economics - Explaining economic policy. Cambridge: MIT Press.

Robilliard, A.-S., F. Bourguignon, and S. Robinson. 2001. Crisis and income distribution: A micro-macro model for indonesia. Mimeo. Washington, DC: The World Bank.

Singh, I., L. Squire, and J. Strauss. 1986. Agricultural household models. Extensions, applications, and policy. Baltimore: The Johns Hopkins University Press.

Todd, P. E., and K. I. Wolpin. 2006. Ex-ante evaluation of social programs. Penn Institute for Economic Research Working Paper 06-022. Philadelphia: University of Pennsylvania. http:// ssrn.com/abstract $=931393$.

Young, J. 2005. Research, policy and practice: Why developing countries are different. Journal of International Development 17: 727-734.

Ousmane Badiane is the Director for Africa at the International Food Policy Research Institute (IFPRI), based in Washington, DC. He oversees the Institute's regional offices for West and Central Africa, in Dakar, Senegal, and Eastern and Southern Africa, in Addis Ababa, Ethiopia. He received a Master's Degree and $\mathrm{PhD}$ in agricultural economics from the University of Kiel in Germany. His awards include being selected as a 2015 Yara Prize Laureate, a Doctoral Degree Honoris Causa from the University of KwaZulu Natal in South Africa and induction as Distinguished Fellow of the African Association of Agricultural Economics.

Christian Henning is professor and chair of agricultural economics, University of Kiel (Germany). He studied economics, agricultural economics, sociology, political science and mathematics. He earned a $\mathrm{PhD}$ in economics, in agricultural economics and in political science. His main areas of specialization are applied political economy and applied economic modelling of agricultural policies. To date he has published five books and various articles in refereed journals including PLoS ONE, American Journal of Agricultural Economics, European Review of Agricultural Economics, Journal of Public Policy, Journal of Mathematical Sociology and Journal of Theoretical Politics.

Eva Krampe is an agricultural sector expert at the European Investment Bank. She studied agricultural economics and earned a $\mathrm{PhD}$ in agricultural economics at the University of Kiel (Germany). Her main areas of specialization are Agricultural Policies in the European Union and Sub-Saharan Africa, Applied Political Economy, Agriculture Value Chain Finance, and Economic Analysis of Agricultural Investment Projects. 
Open Access This chapter is licensed under the terms of the Creative Commons Attribution 4.0 International License (http://creativecommons.org/licenses/by/4.0/), which permits use, sharing, adaptation, distribution and reproduction in any medium or format, as long as you give appropriate credit to the original author(s) and the source, provide a link to the Creative Commons license and indicate if changes were made.

The images or other third party material in this chapter are included in the chapter's Creative Commons license, unless indicated otherwise in a credit line to the material. If material is not included in the chapter's Creative Commons license and your intended use is not permitted by statutory regulation or exceeds the permitted use, you will need to obtain permission directly from the copyright holder.

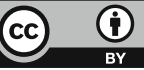

